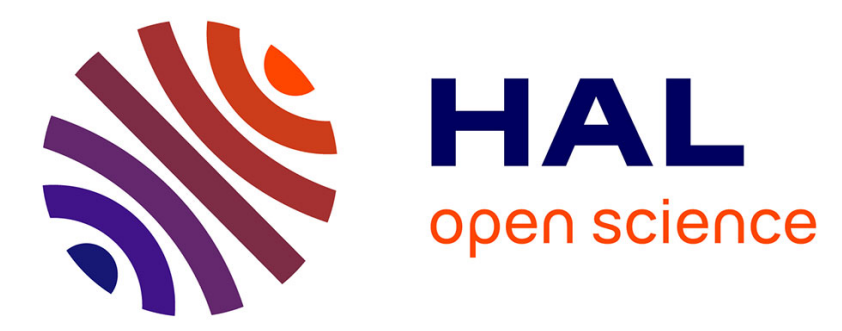

\title{
Nonlinear optical properties and application of a chiral and photostimulable iron(II) compound
}

A Iazzolino, A Ould Hamouda, Ahmad Naïm, Olaf Stefánczyk, Patrick Rosa, Eric Freysz

\section{- To cite this version:}

A Iazzolino, A Ould Hamouda, Ahmad Naïm, Olaf Stefánczyk, Patrick Rosa, et al.. Nonlinear optical properties and application of a chiral and photostimulable iron(II) compound. Applied Physics Letters, 2017, 110 (16), 161908 (5 p.). 10.1063/1.4981254 . hal-01507147

\section{HAL Id: hal-01507147 \\ https://hal.science/hal-01507147}

Submitted on 13 Apr 2017

HAL is a multi-disciplinary open access archive for the deposit and dissemination of scientific research documents, whether they are published or not. The documents may come from teaching and research institutions in France or abroad, or from public or private research centers.
L'archive ouverte pluridisciplinaire HAL, est destinée au dépôt et à la diffusion de documents scientifiques de niveau recherche, publiés ou non, émanant des établissements d'enseignement et de recherche français ou étrangers, des laboratoires publics ou privés.

\section{(ㅇ)(1) $\$$}

Distributed under a Creative Commons Attribution - NonCommercial - NoDerivatives| 4.0 


\title{
Nonlinear optical properties and application of a chiral and photostimulable iron(II) compound
}

\author{
A. IAzzolino, ${ }^{1}$ A. OUld Hamouda, ${ }^{1}$ A. NAÏM, ${ }^{2}$ O. StefánCzYK, ${ }^{2}$ P. Rosa, ${ }^{2}$ ANd E. \\ FREYSZ, \\ ${ }^{1}$ Univ. de Bordeaux, UMR CNRS 5798, LOMA, 351 cours de la libération, 33405 Talence \\ Cedex, France \\ ${ }^{2}$ CNRS, Univ. de Bordeaux, 87 av. du Dr. A. Schweitzer, F-33600 Pessac, France. \\ *eric.freysz@u-bordeaux.fr
}

Abstract: We measure linear absorption, circular dichroïsm, second harmonic and sum frequency generation in the $\left[\Delta-\mathrm{Fe}(\text { phen })_{3}\right]\left(\Delta-\mathrm{As}_{2}(\text { tartarate })_{2}\right),\left[\Lambda-\mathrm{Fe}(\text { phen })_{3}\right]\left(\Lambda-\mathrm{As}_{2}(\text { tartarate })_{2}\right)$ enantiomers of an Fe(II) complex. In the solid state, the chirality of this compound results from the introduction of the $\left(\mathrm{As}_{2}(\text { tartarate })_{2}\right)$ chiral anions. Linear absorption and X-ray diffraction indicate that $\mathrm{Fe}(\mathrm{II})$ is in the low-spin state. Circular dichroïsm reveals that in the solid state, these compounds are chiral, whereas the complexes racemize in solution. A large second harmonic generation signal is recorded using thin films from these two enantiomers. The second-order susceptibility $\chi_{111}^{(2)}$ of these compounds is evaluated across the visible spectral range. It displays a resonance at $520 \mathrm{~nm}$, which is associated with the metal-to-ligand charge transfer occurring within the complex. At its maximum, $\chi_{111}^{(2)}=6.4 \mathrm{pm} \mathrm{V}^{-1}$ is more than 1.4 times larger than the well-known beta- $\mathrm{BaB}_{2} \mathrm{O}_{4}$ nonlinear crystal $\left(\chi_{122}^{(2)} \sim 4.4 \mathrm{pm} \mathrm{V}^{-1}\right)$. Finally, we demonstrate a useful application for a thin film from this compound, which characterizes the cross-correlation of two femtosecond laser pulses. 
Spin crossover complexes (SCO) are well known to exhibit bistability between low-spin and high-spin states. ${ }^{1}$ In Fe(II) compounds, it has been shown that switching between these two spin states can be achieved at room temperature by varying temperature, ${ }^{2}$ pressure, ${ }^{3}$ and chemical environment, ${ }^{4}$ as well as by applying electric, ${ }^{5}$ magnetic,${ }^{6}$ or optical fields. ${ }^{7}$ This has allowed these compounds to be implemented in electronic devices, microelectromechanical systems (MEMS), ${ }^{8}$ thermometers, ${ }^{9}$ chemical sensors, ${ }^{10}$ and so on. However, applications of these compounds are still limited due to the centrosymmetry that most of the SCO compounds usually adopt in solid state. The centrosymmetry forbids this material from exhibiting piezoelectric and electro-optic effects, as well as second harmonic and sum frequency generation. ${ }^{11}$ To further extend the application of SCO compounds, it is necessary to break their natural centrosymmetry. It has recently been shown that introducing a chiral anion to the coordination framework of nanoparticles of SCO polymers makes the complexes display specific chiro-optical (circular dichroïsm) properties. ${ }^{12}$ This simple technique is particularly promising for producing large quantities of chiral complexes. However, this chiral isotropic medium still forbids the occurrence of highly desirable properties such as piezoelectricity and second harmonic generation. ${ }^{13}$ In this paper, we present the optical properties of a noncentrosymmetric chiral compound. Moreover, while this compound does not show thermal SCO in ambient conditions, $\left[\mathrm{Fe}(\text { phen })_{3}\right]^{2+}$ has been extensively studied because of its ultrafast photoswitching between low-spin and high-spin states, ${ }^{14-16}$ thereby paving the way for the design of an ultrafast optical nonlinear photoswitch. Hereafter, we show that it displays second-order nonlinear optical properties. At its maximum, its second-order nonlinear coefficient $\chi_{111}^{(2)}=6.4 \mathrm{pm} \mathrm{V}^{-1}$ is more than 1.4 times larger than the well-known beta- $\mathrm{BaB}_{2} \mathrm{O}_{4}$ nonlinear crystal $\left(\chi_{122}^{(2)} \sim 4.4 \mathrm{pm} \mathrm{V}^{-1}\right)$. Finally, we also show that thin films from these chiral compounds can be used to measure the cross-correlation of two femtosecond laser pulses, 
which demonstrates - thanks to their highly effective second-order optical nonlinear coefficient - their direct and useful application in optics.
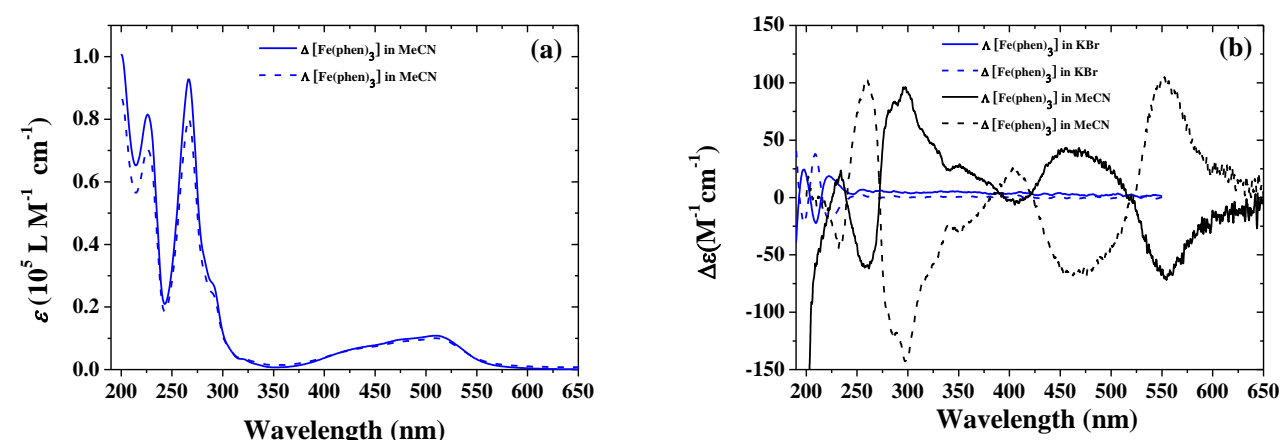

Figure 1: a) UV-visible spectra of $\left[\mathrm{Fe}(\text { phen })_{3}\right]\left[\Delta-\mathrm{As}_{2}(\text { tartarate })_{2}\right]$ (blue solid) and $\left[\mathrm{Fe}(\text { phen })_{3}\right]\left[\Lambda-\mathrm{As}_{2}(\text { tartarate })_{2}\right]$ (blue dashed) in acetonitrile solution. b) Corresponding $\mathrm{CD}$ spectra in $\mathrm{KBr}$ pellets (black solid and dashed lines) and in acetonitrile solution (blue solid and dashed lines).

The synthesis of crystals of $\left[\mathrm{Fe}(\text { phen })_{3}\right]\left(\Delta-\mathrm{As}_{2}(\operatorname{tartarate})_{2}\right)($ phen $=1,10$-phenantroline $)$ and $\left[\mathrm{Fe}(\text { phen })_{3}\right]\left(\Lambda-\mathrm{As}_{2}(\text { tartarate })_{2}\right)$ has previously been reported. ${ }^{17}$ Chiral anions $[\Delta / \Lambda$ $\left.\mathrm{As}_{2}(\text { tartarate })_{2}\right]\left(\mathrm{NBu}_{4}\right)_{2}$ were reacted in a dichloromethane/methanol solution with $\left[\mathrm{Fe}(\mathrm{phen})_{3}\right]^{2+}$. The concentrated solution was left for a few days to obtain the crystalline compound. The absorption spectra of the initial reacting solutions are presented in Figure 1a. In the ultraviolet (UV) region, the three features recorded at 223, 209, and $197 \mathrm{~nm}$ correspond to $\mathrm{n}-\pi^{*}$ forbidden transitions of the tartarate carboxylate groups. For $\left[\mathrm{Fe}(\mathrm{phen})_{3}\right]^{2+}$, one $\pi-\pi^{*}$ phen transition was observed to give a couplet at $260 \mathrm{~nm}$ and $272 \mathrm{~nm} .{ }^{17}$ The absorption bands in the visible range have been attributed to the transfer of electronic charges between the dorbitals of the metal ions and the $\mathrm{p}$ orbital of the ligands of $\left[\mathrm{Fe}(\mathrm{phen})_{3}\right]^{2+}$, named in the literature as a metal-to-ligand charge transfer (MLCT). The circular dichroïsm (CD) spectra of the reacting solutions are presented in Figure $1 \mathrm{~b}$. These $\mathrm{CD}$ spectra show only the contribution of tartarate. The absence of the MLCT bands indicates dissociation of the ion pair caused by the high polarity of acetonitrile, and subsequent racemization of the $\Delta$ - or $\left[\Lambda-\mathrm{Fe}(\text { phen })_{3}\right]^{2+}$ complexes. 
In the saturated solution, single red crystals were formed within a few weeks. Diffraction data of complexes $\left[\mathrm{Fe}(\mathrm{phen})_{3}\right](\mathrm{X})_{2}\left(\mathrm{X}=\Delta\right.$ - or $\left.\Lambda-\mathrm{As}_{2}(\text { tartarate })_{2}\right)$ were collected. The structures could be solved and refined to the point of convergence in the enantiomorphic $P 3_{1} 21 / P 3_{2} 21$ (i.e. 32) space groups, respectively. The crystallographic data are very similar to the analogous complex of $\left[\mathrm{Fe}(\text { phen })_{3}\right]^{2+}$ with $\Lambda$-antimonyl(III) d-tartarate, which crystallizes in the same trigonal chiral point group $32 .{ }^{18}$

The crystal structures of the two eniantomers are isomorphous with the same unit cell. The average Fe-N bond lengths are $1.968(3) \AA$ and $1.970(5) \AA$, respectively, indicating that the $\mathrm{Fe}$ (II) cation is clearly in the low-spin state. To measure the CD spectra, crystals from both eniantomers were mixed with potassium bromide $(\mathrm{KBr})$ powder and pelleted. The $\mathrm{CD}$ spectra of the two enantiomers, which is presented in Figure 1b, reveal alternating bands at 555, 470, and $405 \mathrm{~nm}$ associated with $\left[\mathrm{Fe}(\text { phen })_{3}\right]^{2+}$ MLCT bands, indicating the presence of $\Delta-$ or $[\Lambda-\mathrm{Fe}(\text { phen }) 3]^{2+}$ complexes.

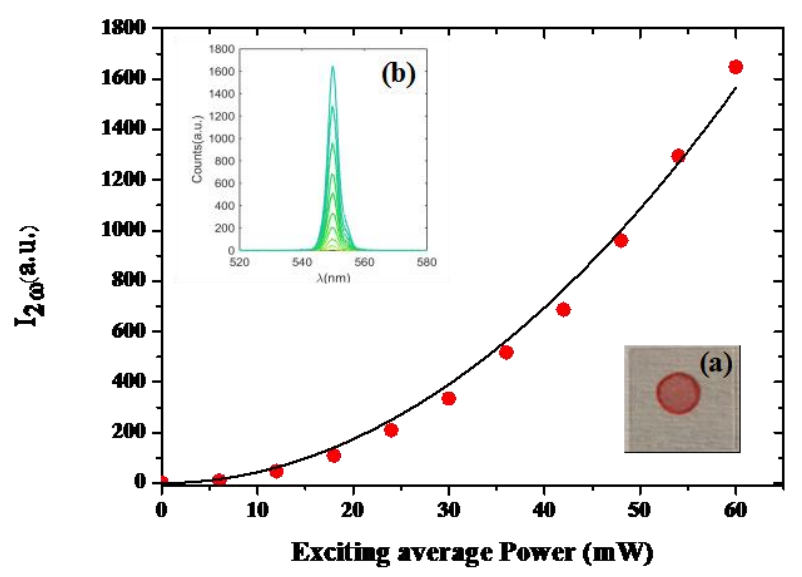

Figure 2: Evolution of the intensity of the second harmonic signal versus the average power of the exciting pulses (dots) and its quadratic fit (solid line). The insets present the picture of the thin films used to perform the experiments (a) and evolution of the spectra (b).

To demonstrate that the chiral complexes we synthesized exhibit nonlinear second-order optical properties, we conducted a second harmonic generation (SHG) experiment. The femtosecond laser pulses, which were provided at a $60 \mathrm{kHz}$ repetition rate by an optical 
parametric amplifier (Light conversion, Orpheus), were focused on the sample by means of a $20 \mathrm{~cm}$ focal length lens. This system provides $\sim 160$ fsec pulses with a central wavelength tunable in the $0.6 \mu \mathrm{m}-2.4 \mu \mathrm{m}$ range. The energy of the laser pulse can be as high as $10 \mu \mathrm{J}$. The SHG signal transmitted at the exit of the sample, or in reflection, is collected by a $5 \mathrm{~cm}$ focal length lens and focused at the entrance slit of a spectrometer connected to a chargecoupled device (CCD) camera. To reject the light at the fundamental laser frequency, a filter was inserted in front of the spectrometer. The sample we studied was prepared as follows. Micro-crystallites of the compounds were dissolved in N,N'-Dimethylformamide (DMF, 10$15 \mathrm{mg} / \mathrm{mL})$. A small volume of this solution $(\approx 30 \mathrm{uL})$ was dropped on a microscope cover glass and dried under vacuum for a few hours. After drying, a thin film formed, which comprised small crystallites a few micrometers in size that were randomly dispersed over the cover glass. X-ray diffraction of the films confirmed that the 32 space group structure observed in the bulk is preserved in the films. Hence the sample can be regarded as a thin film of randomly oriented micro-crystallites. A picture of the prepared sample is presented in Figure 2a. Using an atomic force microscope, the thickness of the film was evaluated to be $2.2 \pm 0.2 \mu \mathrm{m}$. The spectra of the SHG signals recorded for the $\left[\mathrm{Fe}(\mathrm{phen})_{3}\right]\left(\Delta-\mathrm{As}_{2}(\operatorname{tartarate})_{2}\right)$ thin film, when excited at $\lambda=1100 \mathrm{~nm}$, are presented in Figure $2 \mathrm{~b}$. These spectra are centered at $\lambda / 2=550 \mathrm{~nm}$. Moreover, as expected for a non-phase-matched optical second-order nonlinear phenomenon, the amplitude SHG signal evolves as the square of the fundamental pulse intensity (Figure 2). Very similar data were obtained with the $\left[\mathrm{Fe}(\mathrm{phen})_{3}\right](\Lambda$ $\left.\mathrm{As}_{2}(\text { tartarate })_{2}\right)$ thin film. This ensemble of results clearly indicates that the recorded signal does, indeed, result from SHG.

We performed the same experiment on a film obtained by drop-casting a racemic solution of $\left[\mathrm{Fe}(\text { phen })_{3}\right]\left(\Delta-\mathrm{As}_{2}(\text { tartarate })_{2}\right)$ and $\left.\mathrm{Fe}(\text { phen })_{3}\right]\left(\Lambda-\mathrm{As}_{2}(\text { tartarate })_{2}\right)$. Under the same experimental conditions, we could not detect any SHG signal. This result is in agreement with the X-ray 
measurement we performed and the absence of circular dichroïsm. It confirms that this sample is not optically active and, therefore, does not exhibit any second-order nonlinear optical activity.
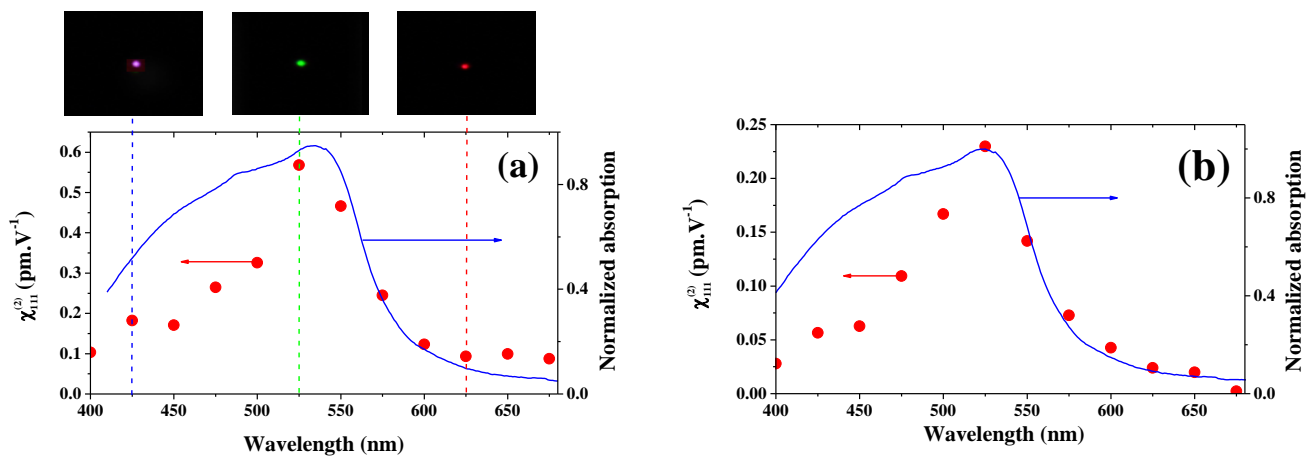

Figure 3: a) Evolution of the susceptibility of the $\left[\mathrm{Fe}(\mathrm{phen})_{3}\right]\left(\Delta-\mathrm{As}_{2}(\text { tartarate })_{2}\right)$ thin film recorded versus the central wavelength of the second harmonic. The insets are pictures of the sample upon excitation when the room light is off. The central bright spot corresponds to the diffusion of the second harmonic signal. b) Evolution of the susceptibility of the $\left[\mathrm{Fe}(\mathrm{phen})_{3}\right]\left(\Lambda-\mathrm{As}_{2}(\operatorname{tartarate})_{2}\right)$ thin film recorded versus the central wavelength of the second harmonic signal.

We measured the SHG signal's evolution as we tuned the central wavelength of the excitation pulses from 1,400 nm to $800 \mathrm{~nm}$. As shown in the inset of Figure 3a, with our setup, the SHG signal generated at the surface of our thin films of $\left[\mathrm{Fe}(\mathrm{phen})_{3}\right]\left(\Delta-\mathrm{As}_{2}(\text { tartarate })_{2}\right)$ could be seen with the naked eye. To infer the effective nonlinear coefficient $\chi_{\text {eff }}^{(2)}$ of our samples, the recorded SHG signals were normalized against the signal we recorded under the same experimental conditions for a $5.25 \mathrm{~mm}$ thick $\alpha$-Quartz crystal cut along the $\mathrm{z}$ axis. This latter crystal symmetry belongs to the same 32-point group. Therefore, for SHG, its secondorder nonlinear susceptibility tensor exhibits the same nonvanishing tensor elements, namely, $\chi_{111}^{(2)}=-\chi_{122}^{(2)}=-\chi_{221}^{(2)}$. In $\alpha$-Quartz, $\chi_{111}^{(2)} \sim 0.6 \mathrm{pm} / \mathrm{V}$ is almost constant over the whole visible and near infrared (IR) spectral range. For a microcrystalline powder belonging to the 32-point group, it can be shown that $\chi_{e f f}^{(2)}=\sqrt{10 / 105} \chi_{111}^{(2)} \cdot{ }^{19}$ As shown in Figure 3, and at variance with the second harmonic signal (SHS) we recorded in $\alpha$-Quartz, the SHS we 
recorded in $\left[\mathrm{Fe}(\text { phen })_{3}\right]\left(\Lambda-\mathrm{As}_{2}(\text { tartarate })_{2}\right)$ strongly increased as we tuned the central wavelength of the laser pulses toward $\lambda=1050 \mathrm{~nm}$. Using the procedure detailed in the supplementary material, we evaluated that at maximum, $\chi_{111}^{(2)}>0.6 \mathrm{pm} \mathrm{V}^{-1}$. This value is already comparable with $\alpha$-Quartz. We performed the same experiment on the $\left[\mathrm{Fe}(\mathrm{phen})_{3}\right](\Lambda$ $\left.\mathrm{As}_{2}(\text { tartarate })_{2}\right)$ thin film. Compared to $\left[\mathrm{Fe}(\mathrm{phen})_{3}\right]\left(\Delta-\mathrm{As}_{2}(\text { tartarate })_{2}\right)$, the absorption of this thin film is about four times smaller, indicating a lower crystallite concentration per square centimeter. The evolution of the normalized absorption and nonlinear coefficient is presented in Figure 3b. Here, again, a clear resonance of the $\chi_{111}^{(2)}$ across the MLCT absorption of these compounds is clearly evidenced. However, for this sample at maximum, we evaluated $\chi_{111}^{(2)}>0.24 \mathrm{pm} \mathrm{V}^{-1}$. Many factors, such as the concentration and the size of the microcrystallites, may account for this discrepancy.

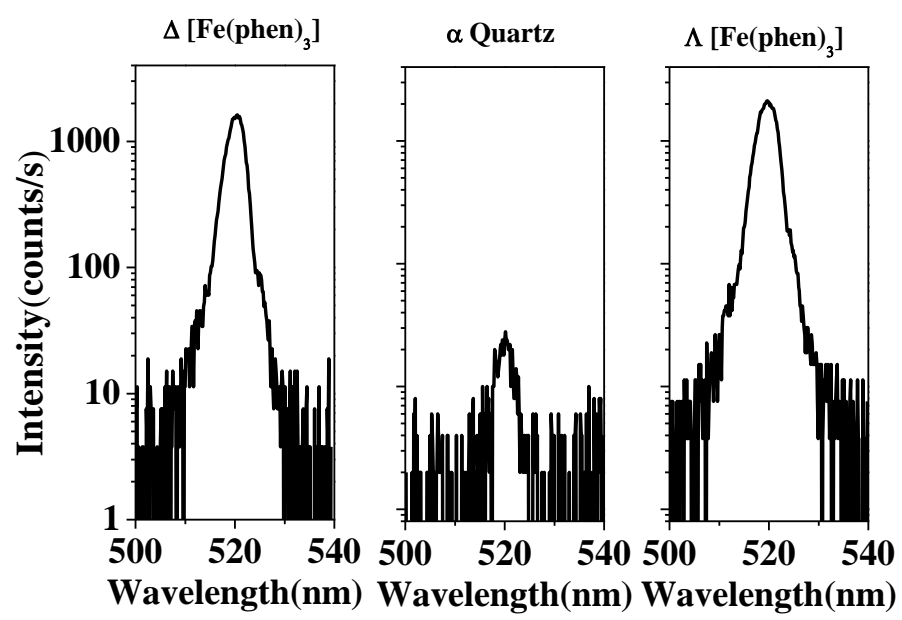

Figure 4: Evolution of the spectra of the $\left[\mathrm{Fe}(\text { phen })_{3}\right]\left(\Lambda\right.$ or $\left.\Delta-\mathrm{As}_{2}(\text { tartarate })_{2}\right)$ and $\alpha$-Quartz powder at fixed excitation power.

We therefore performed another SHG experiment using microcrystalline powder $\left[\mathrm{Fe}(\text { phen })_{3}\right]\left(\Delta-\mathrm{As}_{2}(\text { tartarate })_{2}\right),\left[\mathrm{Fe}(\text { phen })_{3}\right]\left(\Lambda-\mathrm{As}_{2}(\text { tartarate })_{2}\right)$ and $\alpha$-Quartz. The crystallites of the iron compound, a few tens of micrometers in size, were sandwiched between two microscope cover slides, slightly pressed and excited at $1040 \mathrm{~nm}$ with $75 \mathrm{~nJ}$. Then, under the same experimental conditions, the SHG spectrum amplitude for each enantiomer was 
compared to the SHG signal produced by $\alpha$-Quartz powder of a few micrometers in size. Figure 4 displays the SHG signals we recorded. The SHG signals of $\Lambda$ and $\Delta$ enantiomers have almost the same amplitude. We could record the SHG signal for more than 20 minutes without any noticeable change. The ratio between these SHG signals and $\alpha$-Quartz SHG signal is $\sim 100$. The SHG signal being proportional to the square of the effective susceptibility of the sample, these measurements indicate that, neglecting the absorption of our sample and the difference in coherence length with $\alpha$-Quartz, $\chi_{111}^{(2)}\left(\left[\mathrm{Fe}(\text { phen })_{3}\right](\Lambda-\Delta)\right) \cong 10 \chi_{111}^{(2)}(\alpha-$ Quartz) $\approx 6.4 \pm 0.5 \mathrm{pm} \mathrm{V}^{-1}$. This value is about 1.4 (Resp. 7.6) times greater than $\chi_{122}^{(2)} \sim 4.4 \mathrm{pm} \mathrm{V}^{-1}$ (Resp. $\chi_{123}^{(2)} \sim 0.84 \mathrm{pm} \mathrm{V}^{-1}$ ) of the well-known beta-BaB $\mathrm{Ba}_{4}$ (BBO) (Resp. $\left.\mathrm{KH}_{2} \mathrm{PO}_{4}(\mathrm{KDP})\right)$ nonlinear crystal.

The chiral compounds we synthesized exhibit a second-order susceptibility that compares very well to well-known nonlinear crystals, but it does not guarantee their utility. To evidence their simple and direct use, we measured the second-order cross-correlation between two femtosecond laser pulses, using either the thin films or thin BBO crystal and compared the experimental results. The experimental set-up we used to perform this measurement is depicted in Figure 5. Two parallel femtosecond laser pulses centered at frequency $\omega_{1}$ and $\omega_{2}$, delayed in time by $\tau$, are slightly focused on the sample. The output of the thin film is filtered by a colored glass, and only the SHG signals are transmitted. When the two femtosecond pulses are well delayed in time, SHG signals at frequency $2 \omega_{1}$ and $2 \omega_{2}$ are recorded in the direction $\overrightarrow{k_{1}}$ and $\overrightarrow{k_{2}}$ of the exciting pulses. When the two laser pulses temporally and spatially overlap in the thin films, a sum frequency generation (SFG) at the frequency $\omega_{1}+\omega_{2}$, is produced in the direction $\overrightarrow{k_{1}}+\overrightarrow{k_{2}}$. The latter can therefore be easily discarded from SHG in terms of both direction and frequency. The SFG signal can be written as $I\left(\tau, \omega_{1}+\omega_{2}\right) \propto$ $\int_{-\infty}^{+\infty} I_{1}\left(t, \omega_{1}\right) I_{2}\left(t+\tau, \omega_{2}\right) d t$, where $\tau$ is the temporal delay between the two laser pulses and 
$I_{1}\left(\omega_{1}, t\right)$ and $I_{2}\left(\omega_{2}, t\right)$ is the temporal envelope of the intensity of the two femtosecond pulses. ${ }^{17}$ Therefore $\mathrm{I}\left(\tau, \omega_{1}+\omega_{2}\right)$ is, by definition, proportional to the second-order cross-correlation of the two femtosecond laser pulses. If, as in our experiment, the two pulses are considered to have the same temporal width (i.e. $\mathrm{I}_{1,2}(\mathrm{t}, \omega)=\mathrm{I}_{0} \exp \left(-4 \ln 2 \mathrm{t}^{2} / \tau_{\mathrm{p}}^{2}\right)$ ), the second-order crosscorrelation becomes a second-order autocorrelation, and it can be written as $\mathrm{I}\left(\tau, \omega_{1}+\omega_{2}\right) \propto \exp (-$ $\left.4 \ln 2 \tau^{2} / 2 \tau_{\mathrm{p}}{ }^{2}\right)^{17}$ Hence, the FWHM of the autocorrelation trace is $\tau_{\mathrm{c}}=\sqrt{ } 2 \tau_{\mathrm{p}}$.
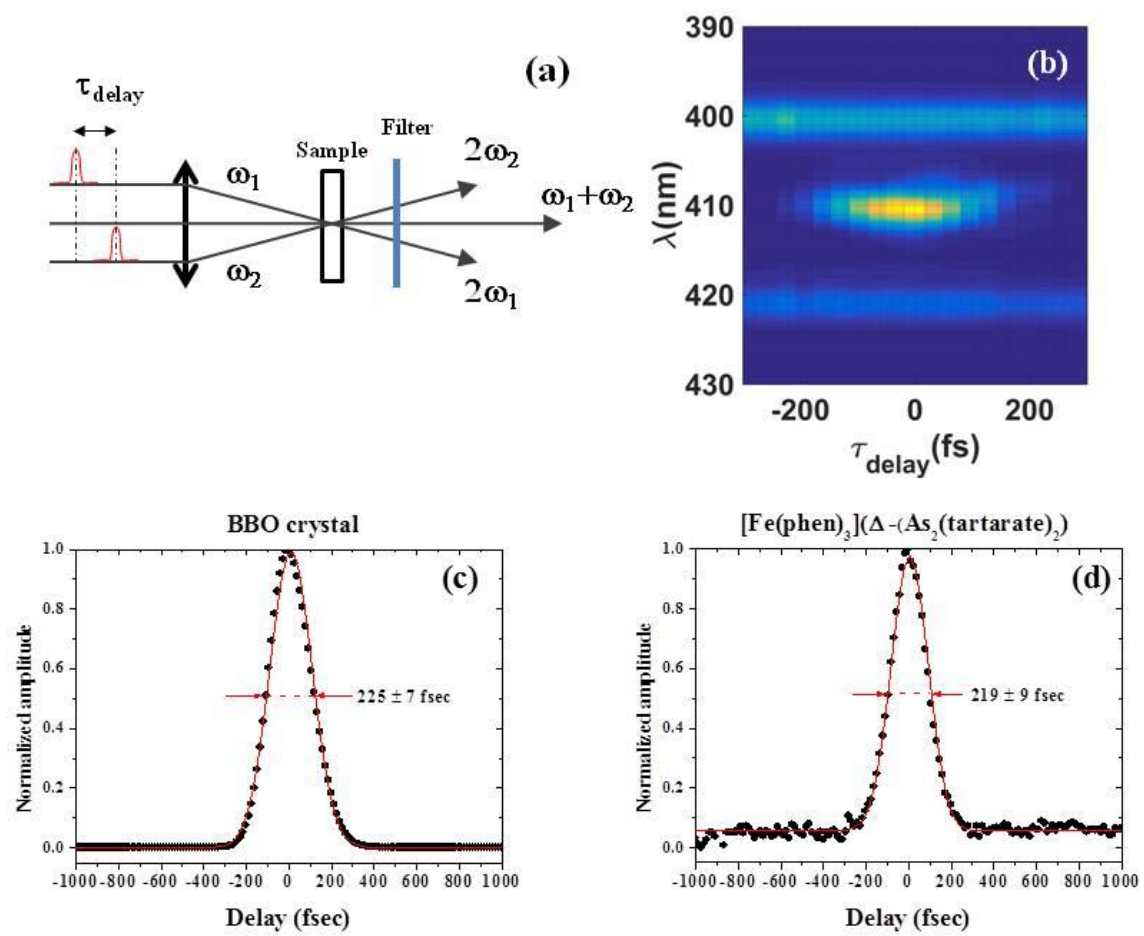

Figure 5: (a) Sketch of the experimental set-up. (b) Spectra recorded for the second-harmonic and sumfrequency signal versus the delay t between the two laser pulses; (c-d). Cross-correlation signal recorded in $\mathrm{BBO}(\mathrm{c})$ and $\left[\mathrm{Fe}(\text { phen })_{3}\right]\left(\Delta-\mathrm{As}_{2}\left(\operatorname{tartarate}_{2}\right)\right.$ thin film (d).

In the experiment, we slightly focused the laser beams on the $\left[\mathrm{Fe}(\text { phen })_{3}\right](\Delta$ $\left.\mathrm{As}_{2}(\text { tartarate })_{2}\right)$ thin film, and the central wavelength of the two linearly polarized femtosecond laser pulses were $\lambda_{1}=800 \mathrm{~nm}$ and $\lambda_{2}=840 \mathrm{~nm}$, respectively. We then focused the output of this second-order auto-correlator on the entrance slit of a spectrometer connected to a CCD and recorded the evolution of the signal versus the time delay $\tau$ between the two 
femtosecond laser pulses. As displayed in Figure 5b, whatever the delay $\tau$, we recorded an SHG signal at $400 \mathrm{~nm}$ and $420 \mathrm{~nm}$, and this was the case whatever the respective orientation of the linear polarization of the two laser pulses. However, an SFG signal was recorded at the wavelength $\left(\lambda_{1} / 4+\lambda_{2} / 4\right)=410 \mathrm{~nm}$ only when the two femtosecond laser pulses temporally overlapped during $230 \mathrm{fsec}$, again, whatever the respective orientation of the linear polarization of the two laser pulses. To measure more quantitatively the FWHM of the crosscorrelation trace, we removed the spectrometer, modulated the intensity of the two femtosecond laser beams at a frequency of $\mathrm{f}_{1}$ and $\mathrm{f}_{2}$, respectively, installed a conventional silicium photodiode (Thorlabs, DET10A) connected to a lock-in amplifier (Stanford Research, SR830) locked at the frequency $\mathrm{f}_{1}+\mathrm{f}_{2}$. In front of the photodiode, we inserted an iris that blocked the SHG signal and transmitted the SFG signal. Then, we recorded the output of the lock-in amplifier versus the delay $\tau$ between the two femtosecond pulses. We performed this latter experiment using either a $200-\mu$ m-thick BBO crystal cut for an $800 \mathrm{~nm}$ phasematching condition or a thin film of $\left.\mathrm{Fe}(\text { phen })_{3}\right]\left(\Lambda-\mathrm{As}_{2}(\text { tartarate })_{2}\right)$. For the $\left.\mathrm{Fe}(\text { phen })_{3}\right](\Lambda$ $\left.\mathrm{As}_{2}(\text { tartarate })_{2}\right)$ thin film, the two pulses were either linearly or parallelly polarized. Figure 5c and $5 \mathrm{~d}$ display the cross-correlation signal we recorded. The fitting of the cross-correlation signals indicate that $\tau_{\mathrm{c}}=221 \pm 10$ fsec in both the thin film and the BBO. Hence the duration of our laser pulse is $\tau_{\mathrm{p}}=156 \pm 7$ fsec.

This experiment clearly indicates that these two materials give almost similar results for the laser pulse duration. However, as already mentioned, the BBO crystal needs to be properly cut to satisfy the phase-matching condition for SHG and SFG at $800 \mathrm{~nm}$. It is worth noting that this phase-matching condition was satisfied for the given linear polarization of the laser pulses. Another interesting aspect is related to the spectral acceptance of the crystal used. ${ }^{20}$ Indeed, the phase-matching condition is only satisfied at the central frequency of the laser pulse. When ultrashort laser pulses are used, only the spectral components around the central 
wavelength of the laser are efficiently converted. Hence to avoid the broadening of the crosscorrelation trace very thin crystals are used. ${ }^{20}$ The typical thickness of such a crystal can be less than $100 \mu \mathrm{m}$. Such crystals are difficult to manufacture over a large area and are usually costly. The cheap and very easy to produce thin films we used circumvent all these drawbacks: these very thin films do not need to be cut and they work with random linear polarization over a broad spectral range. The main drawbacks are related to small light scattering induced by crystallite dispersion and the damage threshold, which we estimated to be $\sim 10^{12} \mathrm{~W} \mathrm{~m}^{-2}$ at $530 \mathrm{~nm}$ using our femtosecond laser pulses. This damage threshold is two orders smaller than BBO.

In conclusion, we demonstrated that $\left[\mathrm{Fe}(\text { phen })_{3}\right]\left(\Delta-\mathrm{As}_{2}(\text { tartarate })_{2}\right),\left[\mathrm{Fe}(\text { phen })_{3}\right](\Lambda$ $\left.\mathrm{As}_{2}(\text { tartarate })_{2}\right)$ crystals exhibit large second-order susceptibility components with an amplitude that surpasses, in the visible range, well-established and largely used nonlinear crystals such as KDP and BBO. We showed that enhancement of the nonlinear coefficient in the visible range is related to the occurrence of an MLCT band of these compounds in the visible range. We also demonstrated that thin films of $\left[\mathrm{Fe}(\mathrm{phen})_{3}\right]\left(\Delta-\left(\mathrm{As}_{2}(\operatorname{tartarate})_{2}\right)\right.$ can be used to measure the cross-correlation of femtosecond pulses. This direct and useful application of these compounds makes it possible to measure the duration of laser pulses. Accordingly, these experiments indicate that it should be possible to record a piezoelectric effect in this chiral SCO compound, thereby opening a new field of applications for these compounds.

\section{SUPPLEMENTARY MATERIAL}

See supplementary material for the description of the calibration procedure we used to determine the $\chi_{e f f}^{(2)}$ of our thin films. 


\section{References}

${ }^{1}$ P. Gütlich and H.A. Goodwin, editors, Spin Crossover in Transition Metal Compounds (Springer, Berlin ; New York, 2004).

${ }^{2}$ P. Gütlich and A. Hauser, Coord. Chem. Rev. 97, 1 (1990).

${ }^{3}$ P. Gutlich, V. Ksenofontov, and A. Gaspar, Coord. Chem. Rev. 249, 1811 (2005).

${ }^{4}$ P.D. Southon, L. Liu, E.A. Fellows, D.J. Price, G.J. Halder, K.W. Chapman, B. Moubaraki, K.S. Murray, J.-F. Létard, and C.J. Kepert, J. Am. Chem. Soc. 131, 10998 (2009).

${ }^{5}$ T. Miyamachi, M. Gruber, V. Davesne, M. Bowen, S. Boukari, L. Joly, F. Scheurer, G. Rogez, T.K. Yamada, P. Ohresser, E. Beaurepaire, and W. Wulfhekel, Nat. Commun. 3, 938 (2012).

${ }^{6}$ A. Bousseksou, N. Negre, M. Goiran, L. Salmon, J.-P. Tuchagues, M.-L. Boillot, K. Boukheddaden, and F. Varret, Eur. Phys. J. B-Condens. Matter Complex Syst. 13, 451 (2000).

${ }^{7}$ C. de Graaf and C. Sousa, Chem. - Eur. J. 16, 4550 (2010).

${ }^{8}$ H.J. Shepherd, I.A. Gural'skiy, C.M. Quintero, S. Tricard, L. Salmon, G. Molnár, and A. Bousseksou, Nat. Commun. 4:2607 (2013).

${ }^{9}$ L. Salmon, G. Molnár, D. Zitouni, C. Quintero, C. Bergaud, J.-C. Micheau, and A. Bousseksou, J. Mater. Chem. 20, 5499 (2010).

${ }^{10}$ C. Bartual-Murgui, A. Akou, C. Thibault, G. Molnár, C. Vieu, L. Salmon, and A. Bousseksou, J Mater Chem C 3, 1277 (2015).

${ }^{11}$ R.W. Boyd, Nonlinear Optics, 3rd ed (Academic Press, Amsterdam ; Boston, 2008).

${ }^{12}$ I.A. Gural'skiy, O.I. Kucheriv, S.I. Shylin, V. Ksenofontov, R.A. Polunin, and I.O. Fritsky, Chem. - Eur. J. 21, 18076 (2015).

${ }^{13}$ M.A. Belkin, Y.R. Shen, and R.A. Harris, J. Chem. Phys. 120, 10118 (2004).

14 J. Tribollet, G. Galle, G. Jonusauskas, D. Deldicque, M. Tondusson, J.F. Letard, and E. Freysz, Chem. Phys. Lett. 513, 42 (2011).

${ }^{15}$ C. Consani, M. Prémont-Schwarz, A. ElNahhas, C. Bressler, F. van Mourik, A. Cannizzo, and M. Chergui, Angew. Chem. Int. Ed. 48, 7184 (2009).

${ }^{16}$ A. Cannizzo, C.J. Milne, C. Consani, W. Gawelda, C. Bressler, F. van Mourik, and M. Chergui, Coord. Chem. Rev. 254, 2677 (2010).

${ }^{17}$ A. Naim, O. Stefańczyk, E. Duverger-Nédellec, M. Zeggar, A. Iazzolino, A Ould Hamouda, Y. Bouhadja, Ph. Guionneau, E. Freysz, and P. Rosa ${ }^{\mathrm{a}}$, Chiral structures and non-linear optical properties of $\left[\mathrm{Fe}(\text { phen })_{3}\right]^{2+}$ complexes, submitted to Inorg. Chemistry 
${ }^{18}$ A. Zalkin, D.H. Templeton, and T. Ueki, Inorg. Chem. 12, 1641 (1973).

${ }^{19}$ S.K. Kurtz and T.T. Perry, J. Appl. Phys. 39, 3798 (1968).

20 J.-C. Diels and W. Rudolph, Ultrashort Laser Pulse Phenomena: Fundamentals, Techniques, and Applications on a Femtosecond Time Scale, 2nd ed (Elsevier / Academic Press, Amsterdam ; Boston, 2006). 


\section{Figure captions}

Figure 1: a) UV-visible spectra of $\left[\mathrm{Fe}(\mathrm{phen})_{3}\right]\left[\Delta-\mathrm{As}_{2}\left(\right.\right.$ tartarate $\left._{2}\right]$ (blue solid) and $\left[\mathrm{Fe}(\text { phen })_{3}\right]\left[\Lambda-\mathrm{As}_{2}(\text { tartarate })_{2}\right]$ (blue dashed) in acetonitrile solution. b) Corresponding $\mathrm{CD}$ spectra in $\mathrm{KBr}$ pellets (black solid and dashed lines) and in acetonitrile solution (blue solid and dashed lines).

Figure 2: Evolution of the intensity of the second harmonic signal versus the average power of the exciting pulses (dots) and its quadratic fit (solid line). The insets present the picture of the thin films used to perform the experiments (a) and evolution of the spectra (b).

Figure 3: a) Evolution of the susceptibility of the $\left[\mathrm{Fe}(\text { phen })_{3}\right]\left(\Delta-\mathrm{As}_{2}(\operatorname{tartarate})_{2}\right)$ thin film recorded versus the central wavelength of the second harmonic. The insets are pictures of the sample upon excitation when the room light is off. The central bright spot corresponds to the diffusion of the second harmonic signal. b) Evolution of the susceptibility of the $\left[\mathrm{Fe}(\text { phen })_{3}\right]\left(\Lambda-\mathrm{As}_{2}(\text { tartarate })_{2}\right)$ thin film recorded versus the central wavelength of the second harmonic signal.

Figure 4: Evolution of the spectra of the $\left[\mathrm{Fe}(\mathrm{phen})_{3}\right]\left(\Lambda\right.$ or $\left.\Delta-\mathrm{As}_{2}(\operatorname{tartarate})_{2}\right)$ and $\alpha$-Quartz powder at fixed excitation power.

Figure 5: (a) Sketch of the experimental set-up. (b) Spectra recorded for the second-harmonic and sum-frequency signal versus the delay t between the two laser pulses; $(c-d)$. Cross-correlation signal recorded in $\mathrm{BBO}(\mathrm{c})$ and $\left[\mathrm{Fe}(\mathrm{phen})_{3}\right]\left(\Delta-\mathrm{As}_{2}(\text { tartarate })_{2}\right)$ thin film $(d)$. 